\title{
PENGARUH MINUMAN BERKARBONASI TERHADAP PERUBAHAN FORCE ANTARA CLOSED COIL SPRING DAN ELASTOMERIC CHAIN :STUDI IN VITRO
}

\author{
Zulfan Muttaqin, Rekka, Riris Aprila \\ Fakultas Kedokteran Gigi, Universitas Prima Indonesia \\ Jl. Belanga No.1,Sei Putih Tengah, Medan. \\ Email: mottakeane@gmail.com
}

\section{KATA KUNCI}

Piranti ortodonti, force, closed coil spring, elastomeric chain, minuman berkarbonasi.

\begin{tabular}{l}
\hline KEYWORDS \\
\hline The orthodontic tool, \\
force, closed coil \\
spring, elastomeric \\
chain, carbonated \\
drinks
\end{tabular}

\begin{abstract}
ABSTRAK
Pendahuluan: Closed coil spring dan elastomeric chain merupakan aksesoris ortodonti yang sering digunakan untuk menghasilkan force dalam menggerakkan gigi. Dimana kedua aksesoris tersebut memiliki sifat degradasi struktur yang disebabkan oleh beberapa faktor seperti $\mathrm{pH}$, suhu dan fluoride. Minuman berkarbonasi merupakan minuman yang mengandung gas karbon dioksida. Karbon dioksida dan bahan acidifier meningkatkan keasaman minuman sehingga meningkatkan keasaman rongga mulut. Adapun tujuan penelitian ini adalah untuk mengetahui perubahan force antara elastomeric chain dan closed coil spring Nikel Titanium (NiTi) yang direndam dalam minuman berkarbonasi. Metode: Jenis penelitian ini adalah eksperimental laboratoris dengan jumlah sampel sebanyak 36. Sampel dikaitkan dalam 1 papan akrilik dan direndam dalam minuman berkarbonasi selama 24 jam, 72 jam, 168 jam dan 240 jam. Kemudian force diukur menggunakan force gauge NK-500 dan dicatat. Hasil: Uji statistik Kruskal Wallis $(\alpha=0,05)$ menunjukkan bahwa minuman berkarbonisasi telah terbukti dapat menurunkan force, baik pada elastomeric chain maupun closed coil spring jika dilakukan perendaman dalam minuman berkarbonasi, dan penurunan force tersebut terbanyak terjadi pada closed coil.
\end{abstract}




\section{PENDAHULUAN}

Maloklusi adalah bentuk oklusi yang menyimpang atau tidak sesuai dari bentuk normal. ${ }^{1}$ Untuk mengatasi maloklusi dapat dilakukan perawatan ortodonti untuk mencapai keseimbangan. ${ }^{2}$ Persentase kasus maloklusi pada tahun 2006 mencapai 89\%. ${ }^{1}$ Banyak hal yang dapat ditimbulkan dari maloklusi, tidak hanya menganggu rasa sakit fisik saja, tetapi dapat mengganggu kualitas hidup seseorang baik secara psikologis, sosial ataupun secara keseluruhan. ${ }^{1}$ Perawatan ortodonti pada umumnya menggunakan piranti yang bertujuan untuk menyalurkan gaya langsung ke gigi agar bergerak ke posisi ideal, yang terdiri dari archwire, braket, aksesori (elastik, pegas ulir, pegas lenting dan magnit).

Dalam ortodonti penerapan force optimal diperlukan untuk pergerakan gigi yang ideal. Penutupan ruang pada lengkung gigi adalah salah satu masalah ortodonti yang sering ditemukan dan diperbaiki dengan menggunakan peralatan ortodonti, seperti elastomer chain dan coil spring. ${ }^{3}$ Elastomeric chain merupkan salah satu aksesoris ortodonti yang sering digunakan untuk menggerakkan gigi dengan cara menghasilkan force.

Elastomeric chain terbuat dari bahan elastomer polyurethane yang pada umumnya memiliki tiga tipe yakni short, medium dan long. Salah satu kekurangan dari elastomeric chain adalah force yang dihasilkan dapat mengalami penurunan ketika diaplikasikan.
Force yang dihasilkan dapat dipengaruhi oleh beberapa faktor seperti flouride, suhu, $\mathrm{pH}$, proses sterilisasi dan stain. ${ }^{4}$

Selain itu coil spring merupakan komponen aktif pada archwire, digunakan untuk mendapatkan ruang atau menggerakkan gigi dan merupakan prosedur umum dilakukan pada perawatan menggunakan alat ortodonti cekat. ${ }^{4}$ Coil spring memberikan kekuatan ringan dan berkelanjutan. Berdasarkan bahan coil spring dibagi menjadi tiga yaitu stainless steel, cobalt chromium dan nickel titanium dan dibagi menjadi dua kelompok, yaitu open coil spring dan closed coil spring. Closed coil spring nikel-titanium (NiTi) berfungsi sebagai sistem pengirim force yang efisien dalam penutupan ruang yang terjadi secara mekanik.

Proses penyerapan air yang terjadi pada polimer merupakan salah satu faktor yang mampu mempengaruhi penurunan force. Disamping itu polimer dengan cepat membentuk jarak antar molekul yang semakin jauh dan force dengan cepat akan mengalami penurunan dalam lingkungan rongga mulut. ${ }^{5}$

Menurut hasil penelitian yang dilakukan oleh nusaresearch pada tahun 2014 mengenai kebiasaan orang Indonesia dalam mengonsumsi minuman berkarbonasi didapatkan bahwa $30,7 \%$ dari responden mengatakan setidaknya 2-3 kali mengkonsumsi minuman ringan berkarbonasi dalam seminggu dan 18,5\% responden mengatakan mengkonsumsi 
minuman ringan berkarbonasi lebih dari 3 kali dalam seminggu. ${ }^{6}$ Menurut World Wide Food (2014) minuman ringan di Indonesia meningkat 48,57\% tiap tahunnya. Minuman ringan berkarbonasi yang paling banyak dikonsumsi oleh responden terdiri dari Cocacola ${ }^{\circledR}(99,4 \%)$, Fanta ${ }^{\circledR}(98,7 \%)$ dan Sprite ${ }^{\circledR}$ $(97,5 \%)^{7}$

Pada minuman berkarbonasi terdapat bahan acidifier dan karbondioksida yang pada umumnya mampu meningkatkan keasaman rongga mulut ${ }^{6}$. Kandungan asam pada minuman berkarbonasi tidak hanya mempengaruhi tubuh dan gigi saja, namun juga kekuatan alat dan bahan yang digunakan pada perawatan ortodonti. ${ }^{8}$

Berdasarkan penjelasan diatas penulis tertarik untuk meneliti tentang pengaruh minuman berkarbonasi terhadap perubahaan force antara closed coil spring dan elastomeric chain. Pengaruh minuman berkarbonasi terhadap perubahan force antara elastomeric chain dan closed coil spring dikarenakan adanya kandungan asam karbonat dalam minuman berkarbonasi dapat mempengaruhi proses degradasi.

\section{METODE}

Jenis penelitian yang digunakan adalah eksperimental laboratoris. Penelitian dilakukan di laboratorium Fakultas Kedokteran Universitas Prima Indonesia pada bulan Desember 2019 dengan sampel elastomeric chain putih dan closed coil spring NiTi. Besaran sampel berdasarkan didapatkan dengan rumus yang terdiri dari 6 sampel di setiap kelompok perlakuan dengan total sampel sebanyak 36 sampel.

Penelitian ini menggunakan papan akrilik berukuran $12 \mathrm{~cm} \times 6,5 \mathrm{~cm}$ dan paku sebagai pendukung untuk mempermudah dalam merenggangkan elastomeric chain dan closed coil spring NiTi dengan jarak $25 \mathrm{~mm}$ seperti pada Gambar 1.

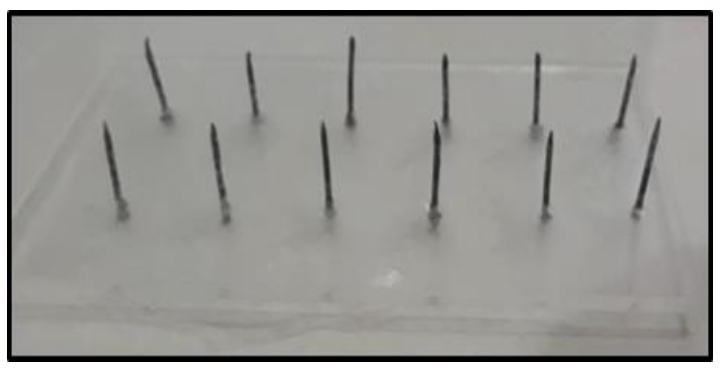

Gambar 1. Papan ukuran $6,5 \mathrm{~cm}$ x $12 \mathrm{~cm}$

Pada penelitian ini terdapat 3 kelompok dengan media perendaman dimana pada kelompok 1 menggunakan saliva buatan, kelompok 2 menggunakan Coca cola ${ }^{\circledR}$ dan kelompok 3 Fanta ${ }^{\circledR}$. Sebelum spesimen direndam, awalnya diukur dan dipotong terlebih dahulu. Kemudian setelah itu direndam di dalam box dengan perendaman berdasarkan kelompok media perandamannya hingga memenuhi box tersebut. Untuk spesimen yang direndam pada saliva buatan dimasukan ke dalam inkubator dengan suhu $37^{\circ} \mathrm{C}$. Lama perendaman setiap spesimen 0 jam, 24 jam, 72 jam, 168 jam dan 240 jam.

Pengujian force dilakukan dengan alat force gauge: NK-500N Dial mechanical gauge pada saat sebelum dan sesudah perendaman. Cara pengukuran dilakukan dengan bantuan 
needle holder untuk menjepit ujung pertama elastomeric chain dan closed coil spring kemudian dikaitkan pada paku yang ada di papan akrilik dan ujung satunya dikaitkan ke lengan pengait alat force gauge tersebut sehingga besaran force yang dihasilkan pada alat pengukur dapat dilihat dari jarum indikator dengan satuan Newton $(\mathrm{N})$.

\section{HASIL}

Dari hasil analisa data penelitian diperoleh rata-rata force pada elastomeric chain dan closed coil spring NiTi setelah direndam dalam minuman berkarbonisasi pada 240 jam lebih kecil dibandingkan rata-rata force pada elastomeric chain dan closed coil spring NiTi setelah direndam dalam minuman berkarbonisasi pada jangka waktu 0 jam, 24 jam, 72 jam, 168 jam dan 240 jam. Kemudian data hasil penelitian tersebut dilakukan uji normalitas dengan Shapiro Wilk

Tabel 1. (Hasil uji normalitas pengaruh minuman berkarbonasi terhadap perubahan force elastomeric chain)

\begin{tabular}{cccc}
\hline Kelompok & \multicolumn{3}{c}{ Shapiro Wilk } \\
\cline { 2 - 4 } dalam Waktu & Statistik & df & sig \\
\hline 24 jam & 0,801 & 18 & 0,022 \\
72 jam & 0,650 & 18 & 0,000 \\
168 jam & 0,815 & 18 & 0,003 \\
240 jam & 0,654 & 18 & 0,000 \\
\hline
\end{tabular}

Tabel 2. (Hasil uji normalitas pengaruh minuman berkarbonasi terhadap perubahan force closed coil spring

\begin{tabular}{cccc}
\hline Kelompok & \multicolumn{3}{c}{ Shapiro Wilk } \\
\cline { 2 - 4 } dalam Waktu & Statistik & df & sig \\
\hline 24 jam & 0,801 & 12 & 0,002 \\
72 jam & 0,650 & 12 & 0,000 \\
168 jam & 0,815 & 12 & 0,000 \\
240 jam & 0,654 & 12 & 0,000 \\
\hline
\end{tabular}

Berdasarkan hasil uji normalitas pada Tabel 1 dan Tabel 2 terdapat data yang tidak normal, sehingga data yang diperoleh akan di lanjutkan dengan uji Kruskal-Wallis

Tabel 3. (Hasil Uji Kruskal Wallis $(\alpha=0,05)$ force elastomeric chain)

\begin{tabular}{cccc}
\hline Waktu & Kelompok & $\begin{array}{c}\text { Mean } \\
\text { Rank }\end{array}$ & p value \\
\hline \multirow{2}{*}{24 jam } & Coca cola ${ }^{\circledR}$ & 9,50 & \\
& Fanta ${ }^{\circledR}$ & 9,50 & 1,000 \\
& Saliva buatan & 9,50 & \\
\hline \multirow{2}{*}{72 jam } & Coca cola ${ }^{\circledR}$ & 6,50 & \\
& Fanta ${ }^{\circledR}$ & 6,50 & $0,000^{*}$ \\
& Saliva buatan & 15,50 & \\
\multirow{2}{*}{168} & Coca cola ${ }^{\circledR}$ & 3,50 & \\
jam & Fanta ${ }^{\circledR}$ & 9,50 & $0,000^{*}$ \\
& Saliva buatan & 15,50 & \\
\hline 240 & Coca cola ${ }^{\circledR}$ & 3,50 & \\
jam & Fanta ${ }^{\circledR}$ & 12,50 & $0,000^{*}$ \\
& Saliva buatan & 12,50 & \\
\hline
\end{tabular}

Dari hasil diatas terlihat nilai force elastomeric chain yang direndam dalam Coca cola ${ }^{\circledR}$ lebih kecil dibandingkan nilai force elastomeric chain yang direndam dalam Fanta® dan saliva buatan.

Tabel 4 (Hasil uji kruskal wallis $(\alpha=0,05)$ closed coil spring nikel titanium (NiTi))

\begin{tabular}{cccc}
\hline Waktu & Kelompok & $\begin{array}{c}\text { Mean } \\
\text { Rank }\end{array}$ & p value \\
\hline \multirow{2}{*}{24 jam } & Coca cola ${ }^{\circledR}$ & 9,50 & \\
& Fanta ${ }^{\circledR}$ & 9,50 & 1,000 \\
& Saliva buatan & 9,50 & \\
\hline \multirow{2}{*}{72 jam } & Coca cola ${ }^{\circledR}$ & 12,50 & \\
& Fanta ${ }^{\circledR}$ & 3,50 & $0,000^{*}$ \\
& Saliva buatan & 12,50 & \\
\hline \multirow{2}{*}{168 jam } & Coca cola ${ }^{\circledR}$ & 12,50 & \\
& Fanta ${ }^{\circledR}$ & 3,50 & $0,000^{*}$ \\
& Saliva buatan & 15,50 & \\
\hline 240 jam & Coca cola ${ }^{\circledR}$ & 15,50 & \\
& Fanta & 6,50 & $0,000^{*}$ \\
& Saliva buatan & 6,50 & \\
\hline
\end{tabular}

Hasil uji Kruskal Wallis $(\alpha=0,05)$ diatas menunjukkan ada perbedaan force closed coil spring nikel titanium (NiTi) yang direndam dalam Coca cola $^{\circledR}$, Fanta ${ }^{\circledR}$ dan saliva buatan dilihat pada jangka waktu 24 
jam, 72 jam, 168 jam dan 240 jam. Dari hasil ini terlihat nilai force closed coil spring nikel titanium (NiTi) yang direndam dalam Fanta ${ }^{\circledR}$ dan saliva buatan lebih kecil dibandingkan dengan nilai force closed coil spring nikel titanium (NiTi) yang direndam dalam Coca cola®.

Berdasarkan hasil uji Kruskal Wallis $(\alpha=$ $0,05)$ diatas, maka dapat dinyatakan ada pengaruh minuman berkarbonisasi terhadap perubahaan force pada elastomeric chain dan closed coil spring nikel titanium (NiTi).

\section{PEMBAHASAN}

Elastomeric chain merupakan suatu alat ortodonti yang sering mengalami penurunan force sepanjang waktu penggunaannya (Suprayugo dkk, 2014). Hasil penelitian ini menunjukkan bahwa rata-rata force pada elastomeric chain mengalami penurunan setelah dilakukan perendaman dalam minuman berkarbonisasi. Semakin lama waktu perendaman, maka semakin rendah force elastomeric chain yang didapatkan. Hasil ini sesuai dengan penelitian yang dilakukan oleh Suprayuogo dkk (2014) didapatkan bahwa terjadi penurunan gaya regang dari elastic chain setelah dilakukan perendaman dalam empat larutan minuman yaitu Teh botol $\AA$, Buavita orange $\AA$, Coca cola ${ }^{\circledR}$ dan aquades dilihat dalam jangka waktu 1 jam, 24 jam, 48 jam, 72 jam, 168 jam dan 336 jam. Minuman ini bersifat asam dan dapat memberikan pengaruh terhadap kekuatan pada alat ortodonti (Hanifa dkk,
2017). ${ }^{9}$ Berdasarkan hasil uji Kruskal Wallis diperoleh terdapat perubahan force elastomeric chain yang direndam dalam minuman berkarbonasi dalam jangka waktu 0 jam, 24 jam, 72 jam, 168 jam dan 240 jam. Penelitian ini sesuai dengan penelitian Nattras (1998) yang menyebutkan bahwa dalam perendaman Coca cola ${ }^{\circledR}$ terjadi penurunan gaya regang power chain dalam perendaman Coca cola ${ }^{\circledR}$ dan larutan turmeric pada 24 jam pertama perendaman mengalami penurunan gaya yang kecil sedangkan setelah 24 jam dan seterusnya penurunan gaya menjadi semakin besar. Hal ini terjadi karena dalam perendaman aquades, air dengan mudah terserap ke dalam power chain sehingga penurunan gaya menjadi lebih besar, sedangkan pada larutan asam pada 24 jam pertama sulit terserap dikarenakan ada senyawa asam yang bereaksi dengan air. ${ }^{6}$ Namun hasil penelitian ini tidak sesuai dengan penelitian Suprayugo dkk (2014) bahwa tidak ada perbedaan gaya regang elastic chain antara perendaman dalam larutan Teh botol $\AA$, Buavita orange $\AA$, Coca cola ${ }^{\circledR}$ dan aquades. Closed coil spring NiTi merupakan alat tambahan dalam perawatan ortodonti cekat yang dapat digunakan sebagai alternatif dalam pergerakan gigi untuk menutup ruang dengan cara menarik coil spring tersebut. Closed coil spring yang terbuat dari bahan stainless steel cenderung lebih murah dan dapat menghasilkan gaya yang besar untuk menggerakkan gigi 
(Santiaji dkk, 2013). ${ }^{9}$ Menurut pendapat Anggolkar dalam Wibowo dkk menyatakan bahwa closed coil spring NiTi adalah salah satu bahan ortodonti yang menunjukkan adanya penurunan kekuatan seiring dengan bertambahnya waktu. ${ }^{10}$ Pernyataan tersebut sesuai dengan hasil penelitian ini yang menunjukkan bahwa adanya penurunan ratarata force dari closed coil spring nikel titanium (NiTi) setelah dilakukan perendaman dalam minuman berkarbonisasi pada jangka waktu 0 jam, 24 jam, 72 jam, 168 jam dan 240 jam. Hasil ini sejalan dengan penelitian yang dilakukan oleh Oshagh dkk (2015) yang mendapatkan hasil bahwa force closed coil spring nikel titanium (NiTi) mengalami degradasi setelah dilakukan perendaman dalam minuman teh selama 24 jam. ${ }^{11}$ Berdasarkan hasil uji Kruskal Wallis $(\alpha=0,05)$ didapatkan bahwa terdapat perubahan dari closed coil spring nikel titanium (NiTi) yang direndam dalam minuman berkarbonasi yang dilihat dalam jangka waktu 0 jam, 24 jam, 72 jam, 168 jam dan 240 jam $(p=0,000)$. Hasil penelitian ini sejalan dengan penelitian yang dilakukan oleh Wibowo dkk (2015) menyatakan bahwa terdapat perbedaan yang bermakna $(\mathrm{p}<0,05)$ antara lama perendaman dalam saliva buatan terhadap kekuatan open coil spring nikel titanium. ${ }^{12}$ Namun, hasil ini tidak sejalan dengan penelitian yang dilakukan oleh Geng dkk (2019) bahwa penurunan force pada closed coil spring nikel titanium (NiTi) tidak tergantung oleh waktu. ${ }^{13}$
Hasil penelitian ini menunjukkan bahwa minuman berkarbonisasi telah terbukti dapat menurunkan force, baik pada elastomeric chain maupun closed coil spring nikel titanium (NiTi) jika dilakukan perendaman dalam minuman berkarbonasi, dan penurunan force tersebut terbanyak terjadi pada closed coil spring nikel titanium (NiTi). Keadaan ini terjadi karena Coca cola ${ }^{\circledR}$ dan Fanta® merupakan minuuman yang memiliki pH asam serta menghasilkan asam karbonat, dimana asam karbonat merupakan golongan asam lemah yang memiliki peran sebagai katalisator air $\left(\mathrm{H}_{2} \mathrm{O}\right)$ kemudian $\mathrm{H}_{2} \mathrm{O}$ diubah menjadi $\mathrm{H}^{+}$dan $\mathrm{OH}$ sehingga ion akan terus meningkat, konsentrasi ion $\mathrm{H}^{+}$akan mengalami reduksi dan ion $\mathrm{H}^{+}$akan berikatan dengan elektron yang terlepas dari hasil oksidasi ion $\operatorname{logam}^{13}$. Semakin asam kondisi lingkungan maka akan semakin banyak reaksi reduksi sehingga dapat memicu terjadinya pelepasan ion-ion logam.Waktu perendaman dapat memberikan pengaruh terhadap force pada elastomeric chain dan closed coil spring nikel titanium (NiTi).Waktu perendaman dapat memberikan pengaruh terhadap force pada elastomeric chain dan closed coil spring nikel titanium $(\mathrm{NiTi})^{14}$.

\section{SIMPULAN}

Berdasarkan hasil penelitian ini maka dapat disimpulkan adanya perbedaan force elastomeric chain dan closed coil spring nikel titanium (NiTi) yang direndam dalam 
minuman berkarbonasi dilihat dalam waktu 0 jam, 24 jam, 72 jam, 168 jam dan 240 jam serta adanya pengaruh minuman berkarbonasi terhadap perubahaan force pada elastomeric chain dan closed coil spring nikel titanium (NiTi)

\section{DAFTAR PUSTAKA}

1. Bishara SE. Textbook of Orthodontics; Saunders company: 2001. 186-207

2. Raharjo,p. Ortodonti dasar edisi 2. Airlangga University Press; 2012. Hal : 2

3. Suprayugo, M., Y.K. Eriwati, dan A. Soufyan. Pengaruh $\mathrm{pH}$ Minuman Dalam Kemasan Terhadap Gaya Regang Power Chain Ortodontik. [skripsi]; Universitas Indonesia; 2014

4. Taufik, H, Y. Kusuma dan D. Joesina. Pengaruh Suhu Terhadap Penurunan Regang Power Chain Ortodontik Dalam Dalam Larutan Saliva Buatan. Universitas Indonesia. Jakarta; 2014

5. Proffit, W.r., Fields, H.W., \& Sarver, D.M. Contemporary Orthodontics (5th Edition). St. Louis, Missouri: Elsevier. 2013

6. Nattras C, Ireland AJ. The Effect of Environmental Factors On The Elastomeric Chain And Nickel-Titanium Coil Spring. Eur J Orthod 1998; 20: 169-176

7. Al Kassar ss. The Force Degradation of Elastomeric Chain In Different Environments And For Different Interval. Al- Radidain Dent J, 2011: 11(2):23-237
8. Mohammed, N, N. Naurie.. The effect of herbal mouthwashes on the forces decay elastomeric chains. International Journal of Medical Research \& Health Sciences, 2017. 6(10): 45-5. Available online at www.ijmrhs.com

9. Hanifa, R.N., H.Sulandjari, dan D. sosantyo. Pengaruh lama perendaman dalam minuman berkarbonisasi terhadap kekuatan kawan stainless steel. Skripsi,Universitas Gadjah Mada. Yogyakarta. 2017

10. Santiaji, W.M., S. Hardjono, dan christinati. Pengaruk jarak dan lama peregangan terhadap besar dan penurunan gaya tarik closed spring nikel titanium. J Keg Gi, 4(3), 2013. 204-210

11. Oshagh, M., F. Khajeh, dan H .R. Fattahi. The effect of different environment mental factors on force degradation of three common systems of orthodontic space closure. Dental Research Journal, 12(1), 2015. 50-56.

12. Wibowo, B., J.C.P. Heryumani, dan D. kurni. Pengaruh besar kompresi dan lama perendaman dalam saliva buatan terhadap kekuatan open coil spring nickel titanium. J Ked Gi, 6(4), 2015. 327-33

13. Geng, H., H. Su, J. Whitley, F.C. Lin, X. $\mathrm{Xu}$, dan C.C. Ko. The effect of orthodontic clinical use on the mechanical characteristic of nickel_titanium closed-coil springs. International Medical Research, 47(2), 2019. 803-814.

14. Ayu, C., Sandra, L. Perbedaan defleksi kawat ortodonti nikel-titanium dan NiTi Epoxy resin. Universitas jember. E-jurnal pustaka kesehatan, vol. 4 (no.3). 2016 